\title{
Laparoscopic Transgastric Pancreatic Débridement
}

\author{
Nicholas J. Zyromski
}

Published online: 29 March 2013

(c) Springer Science+Business Media New York 2013

\begin{abstract}
Open operative debridement has been the traditional approach to patients with pancreatic necrosis. Recently, improved understanding of the disease natural history coupled with significant advances in minimally invasive interventional techniques (both endoscopic and laparoscopic) have led clinicians to apply these minimally invasive interventions to pancreatic debridement. This report details one such minimally invasive approachlaparoscopic transgastric pancreatic necrosectomy. A thorough understanding of this complex and heterogeneous disease process is necessary to select patients properly for the most appropriate therapeutic approach.
\end{abstract}

Keywords Acute pancreatitis - Necrotizing pancreatitis . Pancreatic debridement · Transgastric - Laparoscopic . Postoperative care $\cdot$ Patient selection

\section{Introduction}

Acute pancreatitis is a significant medical problem, accounting for nearly a quarter of a million hospital admissions yearly in the United States [1]. The spectrum of pancreatitis severity is variable; between 15 and $20 \%$ of all patients with acute pancreatitis will develop a severe course of the disease with necrosis of the peripancreatic soft tissue and pancreatic parenchyma: necrotizing pancreatitis (NP) $[2,3]$. A significant number of patients with $\mathrm{NP}$ require intervention to address (peri) pancreatic necrosis. Intervention is indicated primarily for infection,

N. J. Zyromski ( $\square)$

Department of Surgery, Indiana University School of Medicine,

535 Barnhill Drive, RT 130, Indianapolis, IN 46202, USA

e-mail: nzyromsk@iupui.edu but also for local complications as well as chronic failure to thrive-_ "persistent unwellness." $[4,5]$ Historically, pancreatic débridement has been performed as an open operation $[3,5,6,7 \cdot, 8-10]$ Over the years, a number of technical modifications to pancreatic débridement have been reported; ultimately, the goals of operation are the same:

1 Débridement of as much necrotic material is safely possible

2 Wide external drainage of the pancreas

3 Access to the alimentary tract

4 Cholecystectomy (if indicated in biliary acute pancreatitis)

Recently, minimally invasive approaches to treatment of necrotizing pancreatitis have generated a great deal of enthusiasm. These minimally invasive approaches include percutaneous [11], endoscopic [12, 13•], retroperitoneal $[14,15,16 \bullet \cdot$, and transabdominal $[17,18]$.

Regardless of approach, several basic principles hold true in treating necrotizing pancreatitis patients: firstly, this disease is very heterogeneous; therefore, no one approach suits every patient (Fig. 1). Individual treatment MUST be tailored to each specific clinical situation. Secondly, timing of intervention is crucial. Pancreatic surgeons have learned by hard experience that intervention too early in the disease course is fraught with hazard, leading to incomplete débridement and potentially catastrophic hemorrhage [19]. On the other hand, a common mistake is waiting too long to intervene, or more commonly extending a series of incomplete treatments (such as percutaneous or endoscopic intervention) to a protracted clinical course. The patient in this situation reaches a point of such profound malnutrition and physiologic exhaustion that he becomes unsalvageable by any method; $4-5$ weeks from the initial pancreatitis insult seems to be the optimal time for intervention. 
The purpose of this report is to describe our approach to patients with pancreatic and peripancreatic necrosis predominantly isolated within the lesser sac: laparoscopic transgastric pancreatic débridement. Clinical experience with transgastric debridement is scant; therefore, after a brief review, the main focus will be on our approach to patient selection and operative conduct.

\section{History of Transgastric Débridement}

The concept of pancreatic débridement through the posterior stomach wall dates to the first endoscopic intervention in 1996 [12]. In 2002 Ammori reported the first case of laparoscopic transgastric débridement [20], and in 2008 the Freiburg pancreatic surgery group reported a small series of 6 patients approached by a novel laparoendoscopic rendezvous approach [17].

Two groups have reported small series of transgastric débridement via conventional open operative approach. A Danish report of 7 patients treated by this strategy documents zero mortality, two repeat operations, and a mean hospital stay of 18 days [21]. Follow up of these patients was quite short: 3 months. More recently, the Calgary group reported 10 patients (of 51 total necrotizing pancreatitis patients managed surgically) treated by open transgastric débridement. These patients had a longer delay from initial pancreatitis insult to surgery (100 days); one required re-operation and none died [22•]. The longer-term follow up of 18 months documented two late complications-recurrent retroperitoneal abscess and recurrent pseudocyst (the latter ascribed to continued alcohol misuse and chronic pancreatitis.

Two points are notable in this limited experience: first, the potential for major hemorrhage exists when transecting the gastric wall, especially with splenic vein thrombosis and sinistral portal hypertension. The single mortality in the German experience was related to massive hemorrhage-after removing a gastrostomy tube 46 days following initial treatment. Secondly, while the transgastric approach is intuitively attractive particularly in hopes of avoiding pancreatic fistula, long term follow up will be required to support early positive experience with the transgastric technique.

\section{Patient Selection}

The ideal patient to be approached with laparoscopic transgastric technique has a (peri) pancreatic necrosis/fluid collection confined to the lesser sac (Fig. 2). A common occurrence in necrotizing pancreatitis is necrosis of the pancreatic neck parenchyma leaving viable upstream tail and downstream head with disconnection of the main pancreatic duct, the so called disconnected left pancreatic remnant. External drainage in this situation results in a persistent pancreatic fistula that frequently requires reoperative intervention for definitively treatment [23]. Currently accepted practice is to wait at least 4 weeks from the initial insult of pancreatitis prior to débridement; this time period allows consolidation and maturation of the (peri) pancreatic collections and facilitates a single débridement.
Fig. 1 Morphology of (peri) pancreatic collections in necrotizing pancreatitis. Specific interventional approach should be tailored to individual patient anatomy. The figure on the left with collection isolated to the lesser sac is most amenable to transgastric débridement. (Published with permission from Indiana University School of Medicine's Office of Visual Media. Copyright 2013, Indiana School of Medicine's Office of Visual Media.)

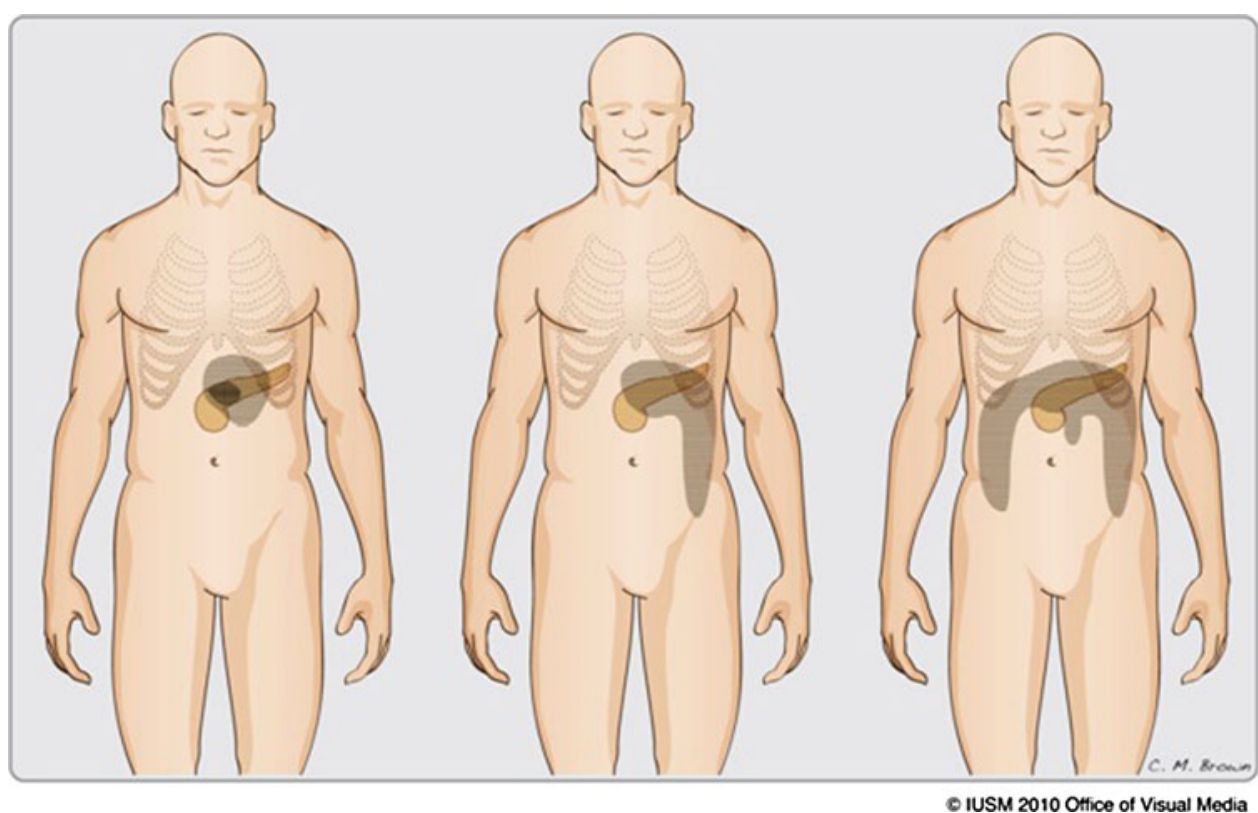



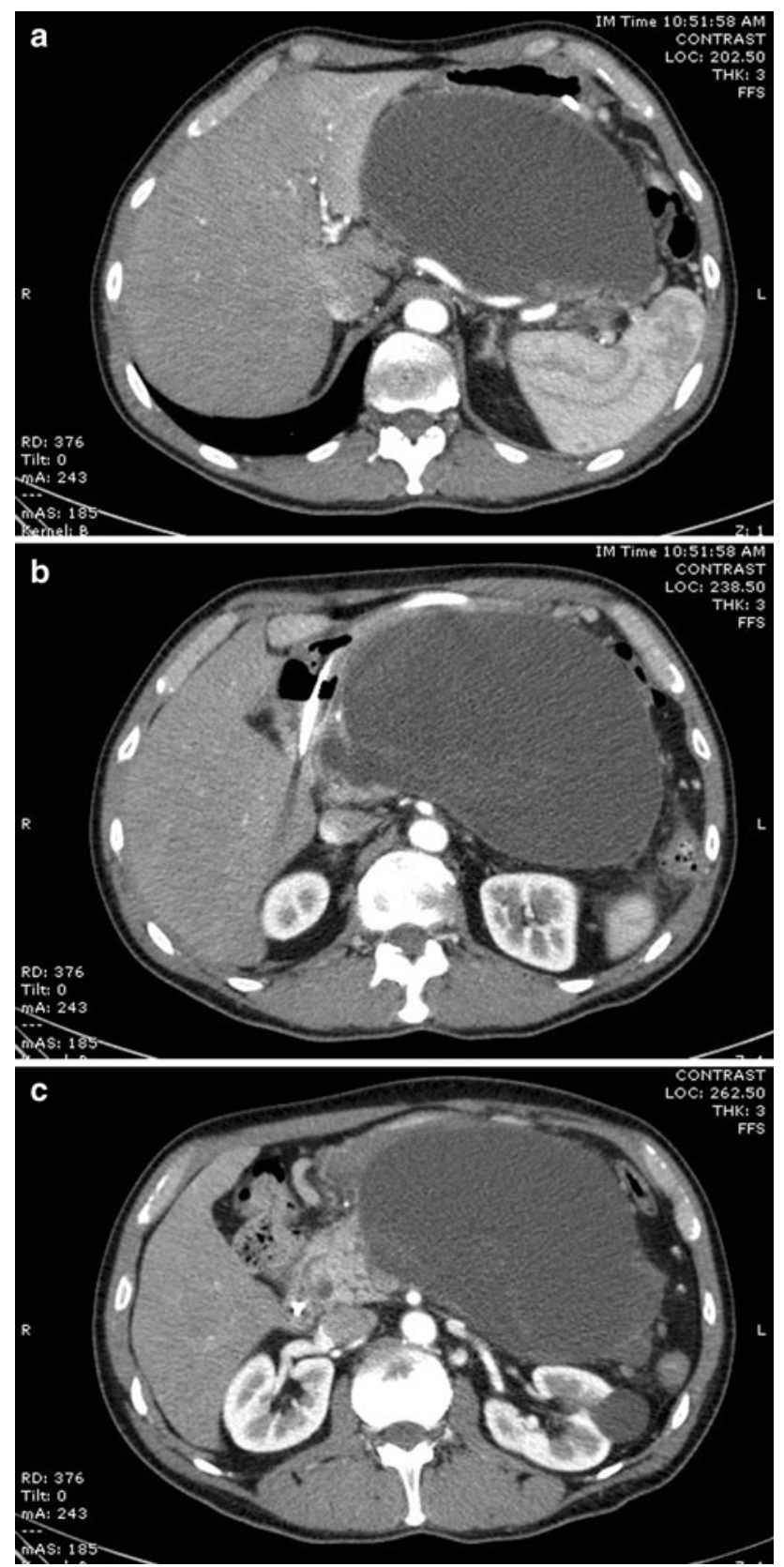

Fig. 2 (a-c-viewed cranial to caudal): Axial cross sectional images (computed tomography) of a patient 6 weeks from incident episode of acute pancreatitis with fluid and solid necrosis consolidated in the lesser sac. This patient was treated successfully with a single laparoscopic transgastric débridement

Early infection $(<4$ weeks into the disease course) is managed with a percutaneous drain to temporize the immediate situation, allowing time for clinical improvement prior to definitive intervention to treat the (peri) pancreatic collections. As many as $30 \%$ of patients may be treated definitively by percutaneous drainage; $[11,14,16 \bullet \cdot]$ however, the majority of patients will need further definitive intervention to completely débride the retroperitoneum.
While percutaneous drainage is not an absolute contraindication to transgastric débridement, the drain tract does provide a route of egress for pancreatic fistula. Infection in and of itself is also not a definite contraindication to the transgastric approach; however, we have seen the best outcomes in patients taken to operation for the indication of symptomatic sterile necrosis (see below). Necrosis tracking down either paracolic gutter represents a relative contraindication to the transgastric approach as this space potentiated in the retroperitoneum permits reaccumulation of pancreatic juice leading to uncontrolled pancreatic fistula.

\section{Advantages and Limitations of the Transgastric Approach}

The laparoscopic transgastric approach to pancreatic débridement offers several real and potential advantages. Ensuring direct communication of the necrosis cavity with the posterior stomach wall allows drainage of the disconnected left pancreatic remnant directly into the alimentary tract and completely avoids the problem of chronic pancreatic fistula related to disconnected left pancreatic remnant (in South America the disconnected pancreatic remnant is referred to as "el Diablo" because of its extremely vexing clinical challenge). The caveat however is that long term follow up of patients treated by transgastric débridement is lacking, and real potential for pancreatic duct stricture with recurrent pancreatitis exists. (Fig. 3) Secondly, the transabdominal approach allows direct access to the gallbladder to perform cholecystectomy and cholangiography at the same setting as pancreatic débridement in patients with biliary pancreatitis. It should be noted however that cholecystectomy in the setting of necrotizing pancreatitis is rarely easy and often extremely challenging. Finally, a theoretical advantage extrapolated from other minimally invasive surgical experience suggests that the minimally invasive approach to pancreatic débridement will likely reduce the incidence of wound complications and ventral hernia-a significant problem in patients under going pancreatic debridement [24].

The major disadvantage of this laparoscopic transgastric débridement lies in the fact that no long-term follow up of these patients exist. In our practice we have seen two patients return more than 1-year following transgastric débridement with recurrent (left sided) pancreatitis related to pancreatic duct stricture in the disconnected left pancreatic remnant (Fig. 3). Data from patients with pancreatic pseudocysts suggest that cystogastrostomy may provide less durable drainage then Roux-en-Y cyst-jejunostomy, though mapping the underlying pancreatic duct anatomy to direct proper drainage is clearly of paramount importance 


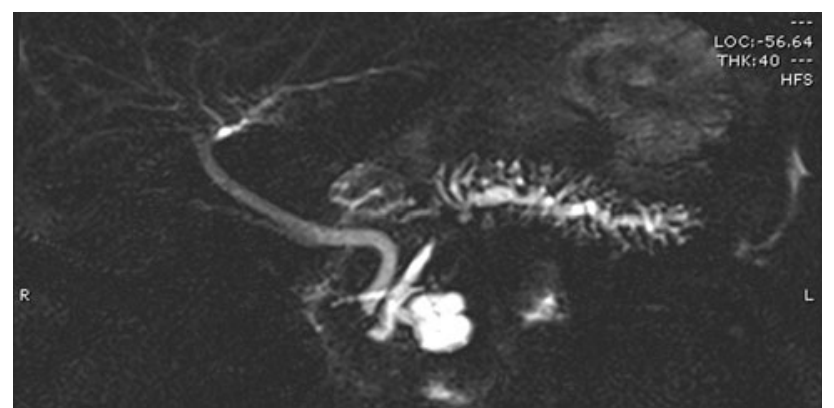

Fig. 3 Magnetic resonance cholangiopancreatography image of a patient 18 months status post transgastric pancreatic débridement. The patient was well for 1 year, then had recurrent episodes of left upper quadrant pain and pancreatitis. The images document stricture of the main pancreatic duct in the pancreatic body, subsequently proved to be upstream from the prior cystogastrostomy

[25]. Time will tell whether this finding is borne out in the setting of pancreatic necrosis.

The transgastric approach is not ideal for all patients with necrotizing pancreatitis: specifically, those with necrosis tracking down the right or left pericolic gutters or down the small bowel mesenteric root may be less than ideally suited for this treatment approach. Once evacuated, these areas become potential spaces, which allow collection of pancreatic secretions that ultimately result in an uncontrolled pancreatic fistula or retroperitoneal abscess. Indeed, we have treated two patients who required early reoperation for reaccumulation of pancreatic necrosis in the pericolic space. Leaving a closed suction drain in the potential space adjacent to the pericolic gutter or small bowel mesenteric root may avoid this problem.

Finally, it is unclear whether preoperative percutaneous drainage to temporize patients with infected pancreatic necrosis is a contraindication to definitive débridement through the stomach. The drain tract offers a site of potential egress for pancreatic secretion and as such at the very least a closed suction drain should be placed adjacent to the drain tract in this clinical setting.

One note regarding patients with pancreatic head parenchymal involvement: this clinical situation portends biliary and possible duodenal involvement (stricture/fistula) in the late term, and commonly causes superior mesenteric vein/portal vein thrombosis with cavernous venous transformation around the pancreatic head and in the porta hepatis. Experienced pancreatic surgeons approach these patients with great caution, expecting protracted clinical involvement.

\section{Surgical Technique}

The patient is placed in a supine position. External compression cuffs are activated for deep vein thrombosis

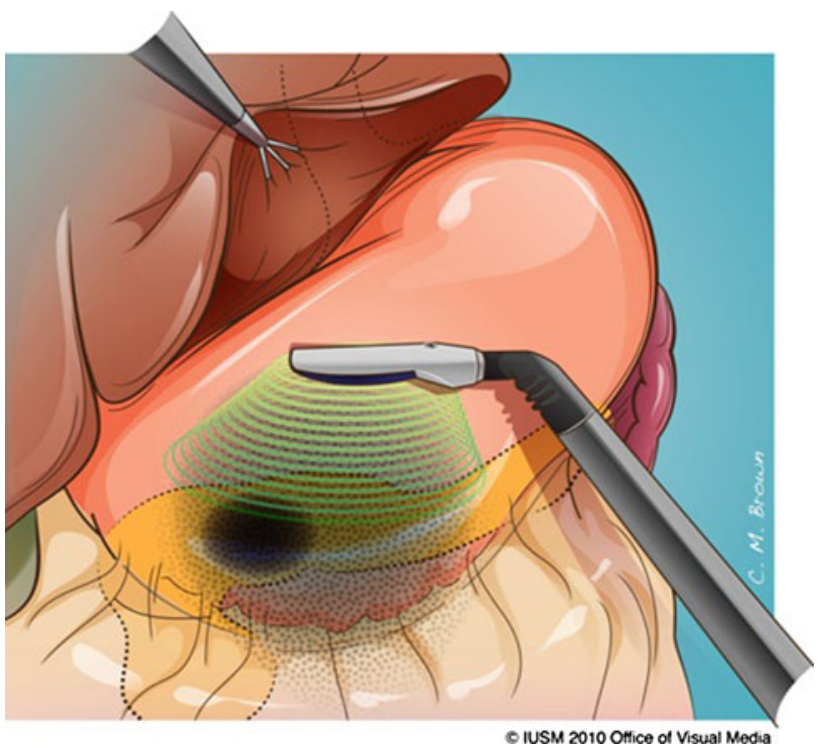

Fig. 4 Intraoperative laparoscopic ultrasonography identifies proper location for anterior gastrotomy, as well as provides the operator an idea of relative volume of fluid and solid material within the walled off (peri) pancreatic collections. (Published with permission from Indiana University School of Medicine's Office of Visual Media. Copyright 2013, Indiana School of Medicine's Office of Visual Media.)

prophylaxis. Given the extremely high incidence of venous thromboembolism in necrotizing pancreatitis patients, it is reasonable to provide preoperative chemical prophylaxis if the operator is comfortable with this strategy.

Adequate intravascular access is also mandatory should the situation of brisk hemorrhage arise. Intravenous antibiotic prophylaxis is administered; if the patient is suspected to have sterile necrosis antibiotics with a good coverage of the general GI flora such as a second generation cephalosporin are a reasonable choice.

Trocars are positioned similar to a laparoscopic distal pancreatectomy. We generally start with a $10 / 12 \mathrm{~mm}$ trocar either at or just cranial to the umbilicus for the camera port. Additional working ports are based on the view of the intra abdominal anatomy. Occasionally a 5-mm subxyphoid port is useful for retraction of a bulky left lateral liver segment.

Intraoperative ultrasonography is an indispensible tool. This modality is particularly useful in laparoscopy where the tactile feedback is limited (Fig. 4). If a gastrostomy feeding tube is in situ, this is prepped into the operative field. Occasionally, the gastrostomy position on the anterior stomach wall may be used to initiate anterior gastrostomy. The abdominal cavity is inspected. Judgment regarding difficulty of cholecystectomy can often be made quickly at this time. Ultrasonography allows precise localization of the (peri) pancreatic collection. The collection's position may be fairly obvious from bulging in the 
anterior wall of the stomach, but is often more cranial than suspected.

Anterior gastrostomy is created and again the site of necrosis/fluid collection is confirmed with ultrasonography through the posterior wall of the stomach. If necessary a long needle may be used to aspirate the cavity area to confirm its location. A more challenging situation exists when the entire collection is solid necrosis, which may be difficult to distinguish from retroperitoneal soft tissue. Incision through the posterior stomach wall is accomplished generally with an energy device such as an ultrasonic scalpel. Usually the cavity has at least a moderate amount of fluid, which is aspirated quickly. We make it a point to culture all of these collections; many patients with suspected sterile necrosis actually harbor sub clinical infection $[3,5,8]$. The posterior gastrotomy and opening into the necrosis cavity is extended either with an energy device or with a linear stapler (Fig. 5). A useful technical maneuver at this point is to place one to two stitches in the posterior stomach wall to use as traction sutures. This maneuver facilitates direct inspection of the necrosis cavity (Fig. 6). It bears repeating that the gastric wall may harbor robust venous varices in the setting of splenic vein thrombosis: caveat operator!

Necrosis is removed through the posterior gastric defect using a blunt grasping instrument. The débrided material is placed into an endoscopic collection bag, minimizing

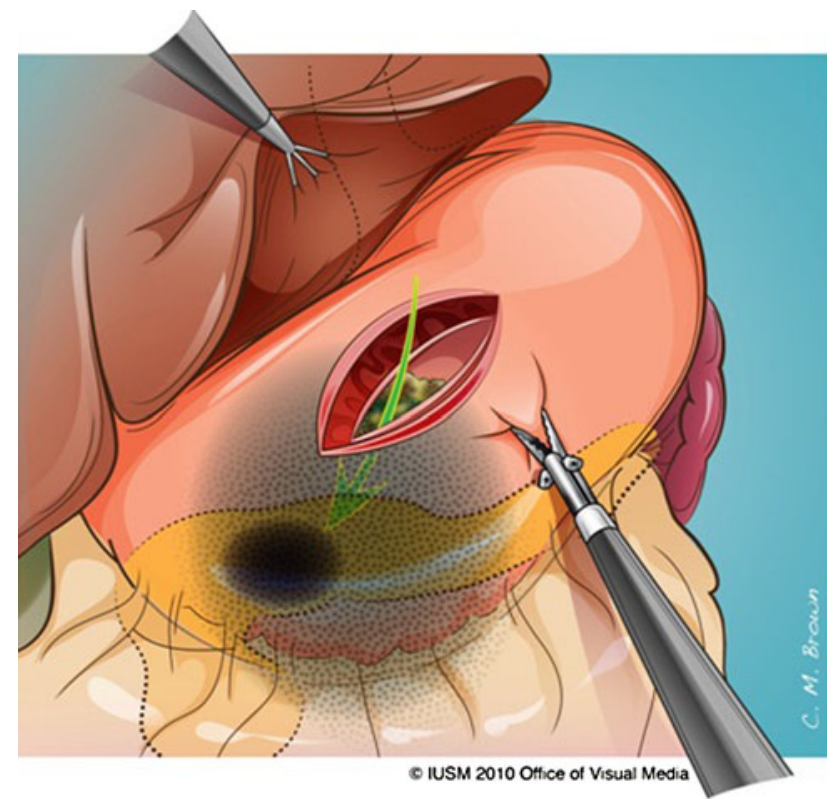

Fig. 5 Posterior gastrotomy is created directly over the collection; this opening may be enlarged with an endovascular stapling device, or with an energy device. Splenic vein thrombosis is common; in this case, the operator should be aware of rich gastric wall venous collaterals. (Published with permission from Indiana University School of Medicine's Office of Visual Media. Copyright 2013, Indiana School of Medicine's Office of Visual Media.) intraperitoneal contamination (Fig. 7). Vigorous irrigation with the suction irrigator may help loosen solid necrosis. Principles of open pancreatic débridement apply to this step; only remove tissue that comes easily. The necrosis cavity is generally quite mature if adequate time has passed since the initial pancreatitis insult (i.e., 4-6 weeks). Visualization of necrosis tracking down the small bowel mesentery root and/or to the right of the middle colic vessels is challenging. Concomitant upper endoscopy is often helpful in this situation. Should endoscopy be performed we occlude the very proximal jejunum with an atraumatic bowel clamp to prevent distention of small bowel with air and loss of working area within the abdominal domain.

Once the necrosis cavity is satisfactory cleared, communication between the cavity and posterior of the wall of the stomach is secured. If this opening has not been created
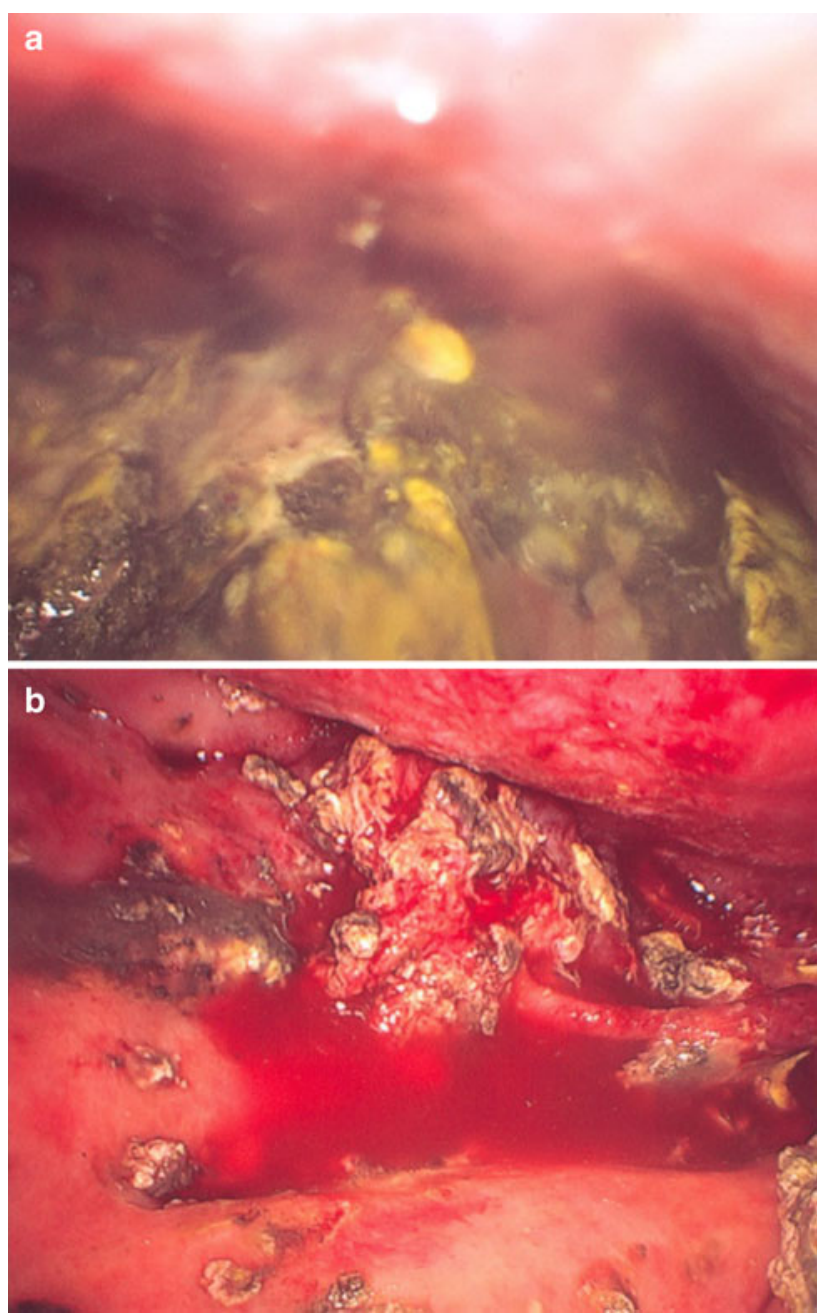

Fig. 6 a Intraoperative view with the laparoscope placed directly within the necrosis cavity. Note presence of solid necrotic material. b Laparoscope in the same cavity after thorough debridement. Note viable, well perfused but disconnected pancreatic tail, as well as the splenic artery in the right of the image 


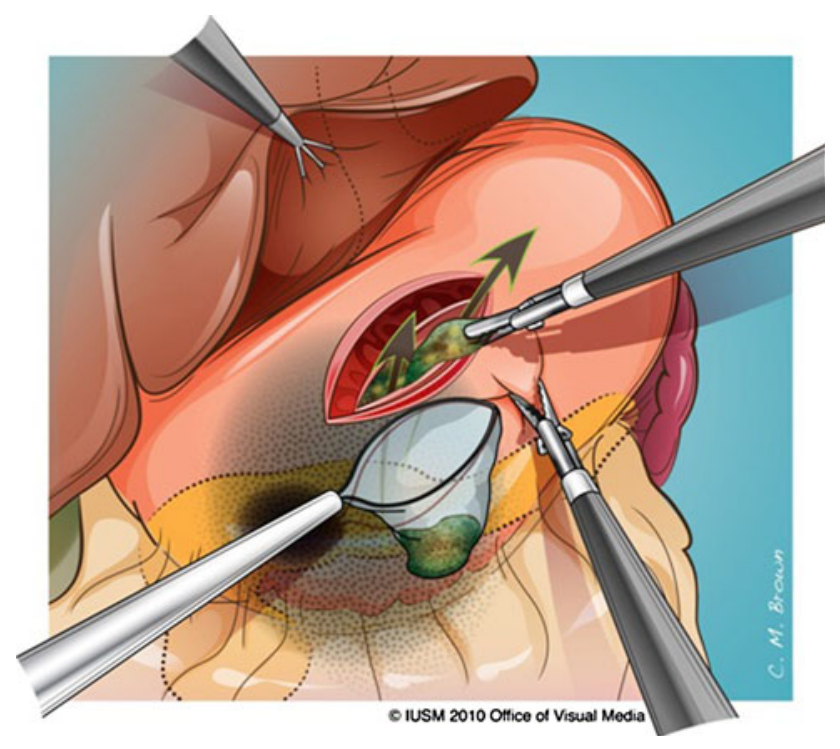

Fig. 7 Placing solid necrosis into a collection pouch minimizes intraabdominal contamination. (Published with permission from Indiana University School of Medicine's Office of Visual Media. Copyright 2013, Indiana School of Medicine's Office of Visual Media.)

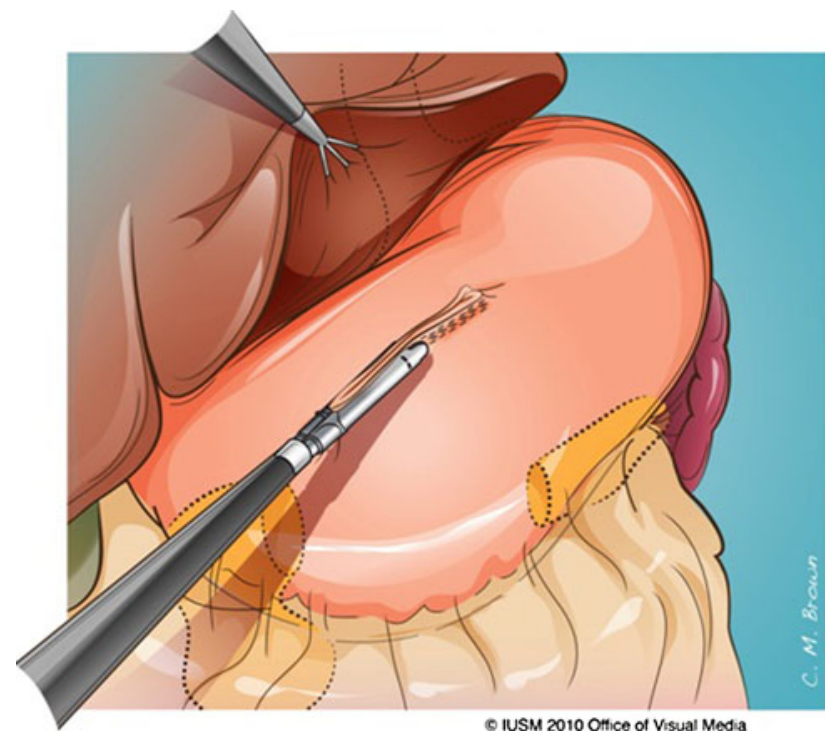

Fig. 8 The anterior gastrotomy may be closed with a stapling device, or by suturing. The latter is preferable in the case of significant gastric wall inflammation. (Published with permission from Indiana University School of Medicine's Office of Visual Media. Copyright 2013, Indiana School of Medicine's Office of Visual Media.)

with an endovascular stapler, running suture is performed at this point. We also biopsy the cystic cavity wall to prove that necrotizing pancreatitis was not caused by a cystic pancreatic neoplasm.

Finally, the anterior stomach wall is closed either with a linear stapler or with suture. (Fig. 8). Should cholecystectomy be indicated and technically feasible, it is performed at this point. We advocate cholangiography in all patients with biliary pancreatitis.

Depending on the patient's nutritional status, access to the alimentary tract is often advised. Based on the operator's preference an enteral feeding tube is placed at this time. Our general preference is to place a gastrostomy tube with jejunal extension, which provides the ability to decompress the stomach through the gastric ports while feeding the alimentary tract downstream (in the jejunum).

\section{Postoperative Care}

Postoperative recuperation is dictated largely by the extent of preoperative debilitation. Many patients have "gastric ileus" in addition to mechanical impingement of the stomach; therefore, tolerance of pure oral intake may take up to several weeks (gastrojejunostomy feeding tubes prove quite valuable in this population). On the other hand, some patients (the "walking wounded" with just "persistent unwellness") may recuperate with remarkable alacrity.

\section{Conclusions}

Transgastric pancreatic débridement appears to be an excellent therapeutic option for select patients with (peri) pancreatic necrosis confined to the lesser sac. Patients treated by this technique must be followed to determine long-term outcomes.

Disclosure Nicholas J. Zyromski declares that he has no conflict of interest.

\section{References}

Papers of particular interest, published recently, have been highlighted as:

- Of importance

•- Of major importance

1. Fagenholz PJ, Fernandez-del Castillo C, Harris NS, Pelletier AJ, Camargo CA Jr. Direct medical costs of acute pancreatitis hospitalizations in the United States. Pancreas. 2007;35:302-7.

2. Frey CF, Zhou H, Harvey DJ, White RH. The incidence and casefatality rates of acute biliary, alcoholic, and idiopathic pancreatitis in California, 1994-2001. Pancreas. 2006;33:336-44.

3. Howard TJ, Patel JB, Zyromski N, et al. Declining morbidity and mortality rates in the surgical management of pancreatic necrosis. J gastrointest surg : Off J Soc Surg Aliment Tract. 2007;11:43-9.

4. Warshaw AL. Damage prevention versus damage control in acute pancreatitis. Gastroenterology. 1993;104:1216-9.

5. Rodriguez JR, Razo AO, Targarona J, et al. Debridement and closed packing for sterile or infected necrotizing pancreatitis: 
insights into indications and outcomes in 167 patients. Ann Surg. 2008;247:294-9.

6. Ashley SW, Perez A, Pierce EA, et al. Necrotizing pancreatitis: contemporary analysis of 99 consecutive cases. Ann Surg. 2001;234:572-9. discussion 9-80.

7. - Beck WC, Bhutani MS, Raju GS, Nealon WH. Surgical management of late sequelae in survivors of an episode of acute necrotizing pancreatitis. J Am Coll Surg. 2012;214:682-8; discussion 8-90. Large report emphasizing need to understand underlying pancreatic ductal anatomy.

8. Buchler MW, Gloor B, Muller CA, Friess H, Seiler CA, Uhl W. Acute necrotizing pancreatitis: treatment strategy according to the status of infection. Ann Surg. 2000;232:619-26.

9. Rau B, Bothe A, Beger HG. Surgical treatment of necrotizing pancreatitis by necrosectomy and closed lavage: changing patient characteristics and outcome in a 19-year, single-center series. Surgery. 2005;138:28-39.

10. Tsiotos GG. Luque-de Leon E, Sarr MG. Long-term outcome of necrotizing pancreatitis treated by necrosectomy. $\mathrm{Br} \mathrm{J}$ surg. 1998;85:1650-3.

11. Freeny PC, Hauptmann E, Althaus SJ, Traverso LW, Sinanan M. Percutaneous CT-guided catheter drainage of infected acute necrotizing pancreatitis: techniques and results. AJR Am J Roentgenol. 1998;170:969-75.

12. Baron TH, Thaggard WG, Morgan DE, Stanley RJ. Endoscopic therapy for organized pancreatic necrosis. Gastroenterology. 1996;111:755-64.

13. - Gardner TB, Coelho-Prabhu N, Gordon SR, et al. Direct endoscopic necrosectomy for the treatment of walled-off pancreatic necrosis: results from a multicenter U.S. series. Gastrointestinal endoscopy 2011;73:718-26. Large, well-controlled, multicenter report of endoscopic approach to transgastric debridement.

14. Horvath K, Freeny P, Escallon J, et al. Safety and efficacy of video-assisted retroperitoneal debridement for infected pancreatic collections: a multicenter, prospective, single-arm phase 2 study. Arch Surg. 2010;145:817-25.

15. Raraty MG, Halloran CM, Dodd S, et al. Minimal access retroperitoneal pancreatic necrosectomy: improvement in morbidity and mortality with a less invasive approach. Ann Surg. 2010;251:787-93.

16. •• van Santvoort HC, Besselink MG, Bakker OJ, et al. A step-up approach or open necrosectomy for necrotizing pancreatitis. N Engl J Med. 2010;362:1491-502. Seminal report of minimally invasive approach to pancreatic necrosis detailing "step-up" approach of the prolific Dutch group.

17. Fischer A, Schrag HJ, Keck T, Hopt UT, Utzolino S. Debridement and drainage of walled-off pancreatic necrosis by a novel laparoendoscopic rendezvous maneuver: experience with 6 cases. Gastrointest Endosc. 2008;67:871-8.

18. Parekh D. Laparoscopic-assisted pancreatic necrosectomy: a new surgical option for treatment of severe necrotizing pancreatitis. Arch Surg. 2006;141:895-902. discussion -3.

19. Mier J, Leon EL, Castillo A, Robledo F, Blanco R. Early versus late necrosectomy in severe necrotizing pancreatitis. Am J Surg. 1997;173:71-5.

20. Ammori BJ. Laparoscopic transgastric pancreatic necrosectomy for infected pancreatic necrosis. Surg Endosc. 2002;16:1362.

21. Ainsworth AP, Nielsen HO, Mortensen MB. Transgastric necrosectomy by open surgery in necrotising acute pancreatitis. Ugeskr Laeger. 2007;169:126-8.

22. - Munene G, Dixon E, Sutherland F. Open transgastric debridement and internal drainage of symptomatic non-infected walled-off pancreatic necrosis. HPB: the official journal of the International Hepato Pancreato Biliary Association 2011;13:234-9. Largest series of open transgastric debridement.

23. Murage KP, Ball CG, Zyromski NJ, et al. Clinical framework to guide operative decision making in disconnected left pancreatic remnant (DLPR) following acute or chronic pancreatitis. Surgery. 2010;148:847-56. discussion 56-7.

24. Al-Azzawi HH, Kuhlenschmidt H, Howard TJ, et al. The burden of incisional hernia in necrotizing pancreatitis: how can we improve? Am J Surg. 2010;199:310-4. discussion 4.

25. Nealon WH, Walser E. Surgical management of complications associated with percutaneous and/or endoscopic management of pseudocyst of the pancreas. Ann Surg. 2005;241:948-57. discussion 57-60. 